\title{
Removal of congo red dye from water using carbon slurry waste
}

Received: 18 October 2004 / Accepted: 24 November 2004 / Published online: 22 December 2004 (C) Springer-Verlag 2004

\begin{abstract}
A cheaper adsorbent has been prepared from carbon slurry waste obtained from National Fertilizer Limited (NFL), Panipat and investigated for the removal of congo red, an anionic dye. Its adsorption on prepared carbonaceous adsorbent was studied as a function of contact time, concentration and temperature. The results have shown that carbonaceous adsorbent adsorbs dye to a sufficient extent $\left(272 \mathrm{mg} \mathrm{g}^{-1}\right)$. A comparative study of adsorption results with those obtained on activated charcoal shows that the carbonaceous adsorbent is $\sim 95 \%$ efficient as compared to activated charcoal. Thus, it can be fruitfully used for the removal of dyes from wastewaters.
\end{abstract}

Keywords Carbon slurry waste Congo red dye . Adsorption $\cdot$ Batch and kinetic studies

\section{Introduction}

Water shortage is a worldwide problem that is further exacerbated by serious water pollution (Zhou 1999). The availability of clean water for various activities is becoming the most challenging task for researchers and practitioners worldwide. The problem is particularly serious for developing countries for three main reasons. First $40 \%$ of the world's population lives in arid and semiarid lands primarily in Asia and Africa, where overpopulation intensifies the problem of water shortage.

This work has been presented at the National Symposium on Biochemical Sciences: Health and Environmental Aspects (BSHEA-2003), Agra, India (2003).

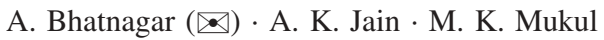

Department of Chemistry,

I.I.T. Roorkee,

Roorkee, 247667, India

e-mail: amit_b10@yahoo.co.in

\section{A. Bhatnagar}

Present address: Swiss Federal Institute for Environmental Science and Technology (EAWAG),

Ueberlandstrasse 133, Duebendorf 8600, Switzerland
}

Secondly, water wastage is a serious problem in many developing countries, in agriculture as well as in industry where outdated technologies are still widely used involving excessive water consumption.

A further problem is that water supplies are being polluted by various chemicals including dyes. Dyes are important water pollutants which are generally present in the effluents of textile, leather, paper and dye manufacturing industries. The worldwide high level of production and extensive use of dyes generates colored wastewaters which cause water pollution. The colored dye effluents are generally considered to be highly toxic to the aquatic biota and affect the symbiotic process by disturbing the natural equilibrium through reduced photosynthetic activity due to the coloration of water in streams. Some dyes are reported to cause allergy, dermatitis, skin irritation, and cancer in humans. Thus, the removal of dyes from effluents before they are mixed up with unpolluted natural water bodies is important.

Amongst several wastewater treatment technologies, adsorption is the most versatile process and widely used (Faust and Aly 1987), for the pollutants removal from wastewaters. Activated carbon is mainly used as adsorbent in the adsorption processes currently in use. However, its widespread applications in wastewater treatment are restricted due to higher cost. In view of the importance of pollution control, efforts have been directed toward developing low cost alternative adsorbents. With this aim, various waste materials as low cost adsorbents (Pollard et al. 1992) have been investigated for the removal of toxic substances from wastewaters. These materials tend to remove more inorganic contaminants as compared to organics. But none has emerged as a sufficiently efficient alternative to activated carbon.

In the present communication, carbonaceous adsorbent, prepared from carbon slurry waste of the fertilizer industry, was tested as adsorbent for dyes with a model system of congo red solutions. Congo red (1-naphthalenesulphonic acid, 3,3'-(4,4'-biphenylenebis(azo))-bis (4-amino) disodium salt) is a benzidine based dye which is known to metabolize to benzidine, a known human 
carcinogen. Exposure to the dye has been known to cause an allergic reaction and possibly, anaphylactic shock (Bhattacharyya and Sharma 2004). The results obtained are compared with those on standard activated charcoal in order to assess the efficacy of the prepared adsorbent.

\section{Experimental}

Materials and solutions

Congo red was procured from B.D.H. (India). All the reagents used were of A.R. grade. Double distilled water was used throughout these investigations.

Preparation of the carbonaceous adsorbent

In India, carbon slurry is produced as a waste in fertilizer plants using fuel oil [Low Sulphur Heavy Stock (LSHS)] as a feed stock. It was treated (Srivastava et al. 1987) with $\mathrm{H}_{2} \mathrm{O}_{2}$ to oxidize the adhering organic material and then washed with distilled water and dried. The thermal activation of dried material was done at $500^{\circ} \mathrm{C}$ (as at this temperature, maximum porosity was observed) in a muffle furnace for $1 \mathrm{~h}$ in the presence of air. After activation, the ash content was removed by treating the material with $1 \mathrm{M} \mathrm{HCl}$ and washed with distilled water and dried. The yield of the finished product was found to be $\sim 90 \%$ and it is now called "carbonaceous adsorbent'. Different mesh sizes were obtained after sieving and kept in a desiccator for further use. Some important characteristics of carbonaceous adsorbent used are: surface area $=380 \mathrm{~m}^{2} \mathrm{~g}^{-1}$; carbon content $=89.8 \%$; methylene blue number $=90$; iodine number $=330$.

\section{Adsorption studies}

Batch method was used to study the adsorption on the prepared carbonaceous adsorbent. For this, a fixed amount of the adsorbent $(0.01 \mathrm{~g})$ was added to $10 \mathrm{ml}$ of dye solution of varying concentrations taken in $50 \mathrm{ml}$ stoppered glass tubes, which were placed in thermostat cum shaking assembly. The solutions were stirred continuously at constant temperature for $2 \mathrm{~h}$ to achieve equilibrium. The concentration of the dye in the residual solutions was subsequently analyzed spectrophotometrically at $\lambda_{\max }$ of $497 \mathrm{~nm}$. The $\mathrm{pH}$ of all solutions in contact with adsorbent was found to be in the range 5.5-6.5.

\section{Results and discussion}

Effect of contact time and concentration

Preliminary experiments were carried out in order to evaluate the contact time needed by the systems to reach equilibrium. The results are shown in Fig. 1. It is seen from Fig. 1 that dye removal seems to occur in two phases. The first phase involved rapid dye uptake in the beginning and $50 \%$ adsorption is completed within 15 min followed by the subsequent removal of the dye which continued for a longer period. Figure 1 also indicates that the time required for equilibrium adsorption is $1.5 \mathrm{~h}$. Thus for all equilibrium adsorption studies, the equilibration period was kept under $2 \mathrm{~h}$. Further, the time required to achieve a definite fraction of equilibrium adsorption was found to be independent of initial concentrations. Similar

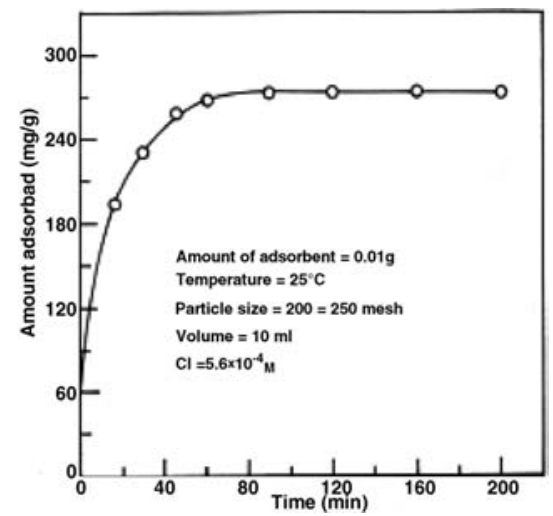

Fig. 1 Effect of contact time on uptake of congo red on carbonaceous adsorbent

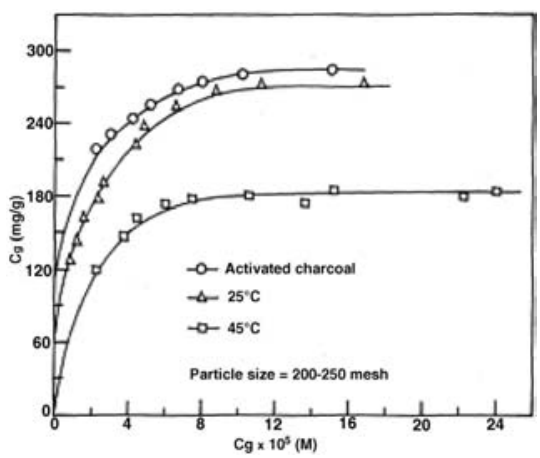

Fig. 2 Adsorption isotherms of congo red on carbonaceous adsorbent at different temperatures and on activated charcoal

observations were also reported by other workers (Poots et al. 1978), and indicate a first-order process.

\section{Adsorption isotherms}

In order to determine the efficacy of the prepared carbonaceous adsorbent, the equilibrium adsorption studies were carried out and the adsorption isotherms are shown in Fig. 2. It is seen from the figure that the adsorption capacity of the adsorbent for congo red is $272 \mathrm{mg} \mathrm{g}^{-1}$.

In order to assess the efficacy of the carbonaceous adsorbent, the results of congo red dye adsorption were compared with standard activated charcoal sample (E. Merck) and incorporated in Fig. 2. It is seen that carbonaceous adsorbent is about $95 \%$ as efficient as standard activated charcoal in removing congo red and therefore, can be fruitfully employed for dye removal from wastewaters.

\section{Effect of temperature}

In order to understand the effect of temperature on the adsorption of dye, experiments were also conducted at $45^{\circ} \mathrm{C}$ and the results are shown in Fig. 2. A comparison of 


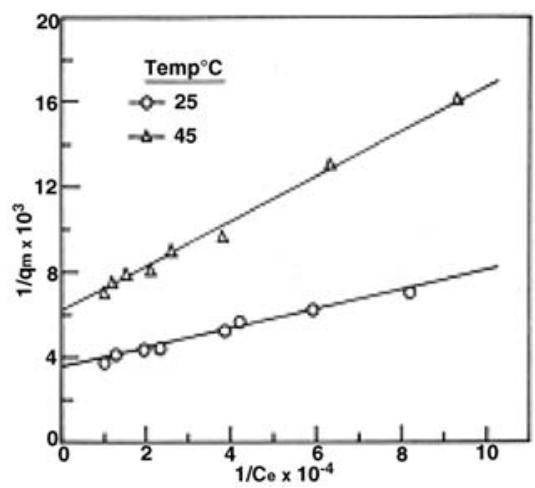

Fig. 3 Langmuir adsorption isotherms of congo red on carbonaceous adsorbent at different temperatures

adsorption isotherms at 25 and $45^{\circ} \mathrm{C}$ shows that adsorption decreases with an increase in temperature indicating that the process is exothermic in nature. The adsorption data was further analyzed and found to conform best to the following Langmuir equation with good correlation coefficients varying from 0.999 to 0.995 .

$\frac{1}{q e}=\frac{1}{q m}+\frac{1}{q m b C e}$

where $q_{\mathrm{e}}$ is amount adsorbed at equilibrium concentration $C_{\mathrm{e}}, q_{\mathrm{m}}$ is the Langmuir constant related to maximum monolayer capacity and $b$ is the Langmuir constant related to energy of adsorption. The plots between $1 / q_{\mathrm{e}}$ and $1 / C_{\mathrm{e}}$ for the adsorption of congo red were drawn in Fig. 3. The values of monolayer capacity $\left(q_{\mathrm{m}}\right)$ were found to be $272 \mathrm{mg} \mathrm{g}^{-1}$ at $25^{\circ} \mathrm{C}$ and $167 \mathrm{mg} \mathrm{g}^{-1}$ at $45^{\circ} \mathrm{C}$. Further, equilibrium constant $\left(b\right.$, in $\left.1 \mathrm{~mol}^{-1}\right)$ have been evaluated from the intercept and slope of these plots and were found to be $9.1 \times 10^{4}$ and $5.5 \times 10^{4}$ at 25 and $45^{\circ} \mathrm{C}$, respectively. Monolayer capacity $\left(q_{\mathrm{m}}\right)$ of the adsorbent for the dye is comparable to the maximum adsorption (Fig. 1) obtained from adsorption isotherms.

The influence of adsorption isotherm shape has been discussed (Weber and Chakravorti 1974) to know whether adsorption is favorable or not in terms of $R_{\mathrm{L}}$, a dimensionless constant referred to as the separation factor or equilibrium parameter. $R_{\mathrm{L}}$ is calculated using the following equation:

$R L=\frac{1}{1+b C_{0}}$

The values of $R_{\mathrm{L}}$ calculated as per the above equation. As the $R_{\mathrm{L}}$ values lie between 0 and $1\left(3.2 \times 10^{-4}\right.$ and $5.2 \times 10^{-4}$ at 25 and $45^{\circ} \mathrm{C}$, respectively), the adsorption isotherm is favorable.

The free energy change $\left(\Delta G^{\circ}\right)$, enthalpy change $\left(\Delta H^{\circ}\right)$ and entropy change $\left(\Delta S^{\circ}\right)$ were calculated using the following equations:

$\Delta G^{\circ}=-R T \ln (b)$ $\ln \left(\frac{\mathrm{b}_{2}}{\mathrm{~b}_{1}}\right)=-\frac{\Delta \mathrm{H}^{\circ}}{\mathrm{R}}\left(\frac{1}{\mathrm{~T}_{2}}-\frac{1}{\mathrm{~T}_{1}}\right)$

$\Delta G^{\circ}=\Delta H^{\circ}-T \Delta S^{\circ}$

for the adsorption process in order to know the nature of adsorption. The free energy change $\left(\Delta G^{\circ}\right)$ was found to be negative with the values 28.3 and $28.9 \mathrm{~kJ} \mathrm{~mol}^{-1}$ at 25 and $45^{\circ} \mathrm{C}$, respectively, whereas entropy change $\left(\Delta S^{\circ}\right)$ values are positive and 28.5 and $28.6 \mathrm{~J} \mathrm{~mol}^{-1} \mathrm{~K}^{-1}$ at 25 and $45^{\circ} \mathrm{C}$, respectively. Further, enthalpy change $\left(\Delta H^{\circ}\right)$ of the present adsorption system was found to be negative with the value $19.9 \mathrm{~kJ} \mathrm{~mol}^{-1}$. These values indicate that the adsorption process is spontaneous and exothermic. Further, positive $\Delta S^{\circ}$ values indicate the affinity of the adsorbent for the dye.

\section{Dynamic modeling}

The kinetics of adsorption is important from the point of view that it controls the process efficiency. Various kinetic models have been used by various workers and different systems conform to different models but the Lagergren's rate equation (Lagergren 1898), is the one most widely used (Panday et al. 1985; Haribabu et al. 1993 ) for the sorption of a solute from a liquid solution. Thus this first-order equation:

$\log (\mathrm{qe}-\mathrm{q})=\log \mathrm{qe}-\frac{\mathrm{k}_{\mathrm{ads}}}{2.303} \mathrm{t}$

where $q_{\mathrm{e}}$ and $q$ are amount of dye adsorbed at equilibrium and at time $t$, in $\mathrm{mg} \mathrm{g}^{-1}$ respectively, and $k_{\text {ads }}$ is the firstorder rate constant, was applied to the present studies of dye adsorption. As such, the values of $\log (q e-q)$ were calculated from the kinetic data of Fig. 1 and plotted against time. The plots so obtained are found to be linear with good correlation coefficients varying from 0.999 to 0.995 indicating that Lagergren's equation is applicable to the dye adsorption on carbonaceous adsorbent and the adsorption process is a first-order process. The first-order rate constant calculated from the plots is found to be $2.08 \times 10^{-4} \mathrm{~min}^{-1}$.

Treatment of effluent of a local dyeing unit

The effluent was obtained from a local dyeing factory using various commercial dyes for dyeing purposes of various textiles. This dye wastewater is characterized by a dark brown color, a pH of 10.3 and Chemical Oxygen Demand (COD) value of $860 \mathrm{mg} \mathrm{l}^{-1}$. The absorption spectra shows that the dye wastewater has four $\lambda_{\max }$ values at 264.0, 473.0, 550.0 and $831.0 \mathrm{~nm}$ with absorbance of 11.1, 25.7, 12.3 and 0.18 at 264.0, 473.0, 550.0 and $831.0 \mathrm{~nm}$, respectively. The treatment of this dye wastewater for dye removal was carried out by passing it through a column (cross sectional area: $0.9 \mathrm{~cm}^{2}$; height: $3.1 \mathrm{~cm}$; mass: $1.0 \mathrm{~g}$ ) of carbonaceous adsorbent, of particles of size 50-200 mesh, at a flow rate of $2.5 \mathrm{ml} \mathrm{min}^{-1}$. 
The monitoring of the column was done spectrophotometrically at $\lambda_{\max }$ values of the solution. For this purpose, a $10 \mathrm{ml}$ aliquot was collected and absorbance determined. It was observed that effluent coming out of the column had almost nil absorbance at all the $\lambda_{\max }$ values upto a total volume of $130 \mathrm{ml}$. After that, the color starts appearing and absorbance increased. This means that a column of $1 \mathrm{~g}$ of carbonaceous adsorbent, as used by us can treat $130 \mathrm{ml}$ of dye wastewater. The COD of the treated dye wastewater was within acceptable limits. Thus, the results show that $1 \mathrm{~kg}$ of prepared carbonaceous adsorbent can treat 1301 of the dye wastewater obtained from the local dyeing factory. It is therefore, reasonable to conclude that the prepared adsorbent can be fruitfully used as an alternative adsorbent for treating dye wastewater.

\section{Conclusions}

The adsorptive capacity of carbonaceous adsorbent for the congo red dye is sufficient $\left(272 \mathrm{mg} \mathrm{g}^{-1}\right)$, and is about $95 \%$ of the adsorptive capacity of standard activated charcoal. This adsorbent, being a low cost ( US\$ $\left.0.1 \mathrm{~kg}^{-1}\right)$ material, can, therefore, be used fruitfully for the removal of dyes from wastewaters. As the carbonaceous adsorbent has shown significant adsorption potential, its columns were successfully used for the removal of effluent of a local dyeing unit. In view of the low cost of this material, the regeneration of the exhausted material need not be done, and it can be disposed of by burning. Further, the present adsorption system is a first-order process.

\section{References}

Bhattacharyya KG, Sharma A (2004) Azadirachta indica leaf powder as an effective biosorbent for dyes: a case study with aqueous congo red solutions. J Environ Manage 71:217-229

Faust SD, Aly OM (1987) Adsorption process for water treatment. Butterworths Publishers, Stoneham

Haribabu E, Upadhya YD, Upadhyay SN (1993) Removal of phenols from effluents by fly ash. Int J Environ Stud 43:169-176

Lagergren S (1898) About the theory of so-called adsorption of soluble substances K. Svenska Vetenskapsad Handl 24:1-39

Panday KK, Prasad G, Singh VN (1985) Copper(II) removal from aqueous solutions by fly ash. Water Res 19:869-873

Pollard SJT, Fowler GD, Sollars CJ, Perry R (1992) Low-cost adsorbents for waste and wastewater treatment: a review. Sci Total Environ 116:31-52

Poots VJP, McKay G, Healy JJ (1978) Removal of basic dye from effluents using wood as an adsorbent. J Water Pollut Control Fed 50:926-935

Srivastava SK, Pant N, Pal N (1987) Studies on the efficiency of a local fertilizer waste as low cost adsorbent. Water Res 21:1389-1394

Weber TW, Chakravorti RK (1974) Pore and solid diffusion models for fixed-bed adsorbers. J Am Inst Chem Eng 20:228-238

Zhou JL (1999) Treating China's water crisis. Chem Ind 19 April 1999 